\title{
Elbow Fracture in Children at Saiful Anwar General Hospital, Nine Years Experiences
}

\author{
Panji Sananta $^{1^{*}}$, Langga Sintong ${ }^{2}$, Budhi Prasetio ${ }^{2}$, Marvin Anthony Putera ${ }^{2}$, Sri Andarini ${ }^{3}$, Umi Kalsum ${ }^{4}$, Respati Suryanto \\ Dradjat $^{2}$ \\ ${ }^{1}$ Faculty of Medicine, Universitas Brawijaya and Orthopaedic and Traumatology Department, Faculty of Medicine, \\ Universitas Brawijaya, Jalan Jaksa Agung Suprapto No. 2, Klojen, Kota Malang, Jawa Timur 65112, Indonesia; ${ }^{2}$ Orthopaedic \\ and Traumatology Department, Faculty of Medicine, Universitas Brawijaya, Jalan Jaksa Agung Suprapto No. 2, Klojen, Kota \\ Malang, Jawa Timur 65112, Indonesia; ${ }^{3}$ Public Health Department, Faculty of Medicine, Universitas Brawijaya, Jalan \\ Veteran no. 2, Klojen, Kota Malang, Jawa Timur 65145, Indonesia; ${ }^{4}$ Pharmacology Department, Faculty of Medicine, \\ Universitas Brawijaya, Jalan Veteran no. 2, Klojen, Kota Malang, Jawa Timur 65145, Indonesia
}

\begin{abstract}
Citation: Sananta P, Sintong L, Prasetio B, Putera MA, Andarini S, Kalsum U, Suryanto Dradjat R. Elbow Fracture in Children at Saiful Anwar General Hospital, Nine Years Experiences. Open Access Maced J Med Sci. 2019 Dec 7(23):4069-4071. https://doi.org/10.3889/oamjms.2019.814 Keywords: Brachial artery injury; Children; Elbow fracture; Gartland classification; Nerve injury; Supracondylar fracture

*Correspondence: Panji Sananta. Faculty of Medicine, Universitas Brawijaya and Orthopaedic and Traumatology Department, Faculty of Medicine, Universitas Brawijaya, Jalan Jaksa Agung Suprapto No. 2, Klojen, Kota Malang, Jawa Timur 65112, Indonesia. E-mail
panjisananta@ub.ac.id pavisanantaubacid

Received: 24-Oct-2019; Revised: 15-Nov-2019; Accepted: 16-Nov-2019; Online first: 12-Dec-2019 Copyright: ๑ 2019 Panji Sananta, Langga Sintong Budhi Prasetio, Marvin Anthony Putera, Sri Andarini, Um Kalsum, Respati Suryanto Dradjat. This is an openaccess article distributed under the terms of the Creative Commons Attibulion

Funding: This research did not receive any financia

Competing Interests: The authors have declared that no competing interests exis
\end{abstract}

\section{Abstract}

AIM: The frequency, incidence, and types of fracture of the elbow are different between children and adult. The epidemiology of elbow fracture in children has been the subject of a limited number of studies. This study aims to observe the pattern of elbow fractures in children 18 years of age and younger, during a nine years period.

METHODS: This is a retrospective study about elbow fracture cases in children 18 years old and younger treated in Saiful Anwar General Hospital Malang in the period of June 2009 until December 2018. The data obtained from the medical record include the age at the time of accidents, fracture site, type of lesion and ipsilateral injuries, time of accidents, and the mechanism of injury.

RESULTS: There is a total of 99 elbow fracture, and there are 62 male $(63 \%)$ and 37 female patients (37\%). The mean age for the entire group is 7.3 years (8.1 years for male and 7.1 years for female). Most cases are supracondylar fracture $(n=77,78 \%)$. The supracondylar fracture is composed of 17 fracture classified to type II, and 60 fracture to type III as classified by Gartland. The most common etiology of fracture is associated with sports, recreational activities, and fall from height of less than two meters. Nerve injury involving the median, radial, and ulnar nerve is seen in eight patients with type III supracondylar fracture. Associated brachial artery injury is seen in four patients with type III supracondylar fractures. A group of 78 patients (79\%) were treated surgically and 21 patients $(21 \%)$ were treated conservatively.

CONCLUSION: The incidence of elbow fracture in children treated in Saiful Anwar General Hospital during a nine years period is 99 patients, with supracondylar fracture Gartland type III being the leading type of this group. Male patients are more common than female patients. Nerve injury was seen in $13.33 \%$ of cases and brachial artery injury was seen $6.67 \%$ with type III supracondylar fracture. Most of the elbow fracture in our institution were treated operatively.

\section{Introduction}

Upper extremity fracture made up $65-75 \%$ of all children fractures and $8-10 \%$ of it involve the elbow region. Elbow fracture in pediatric patients is a great encumbrance treated in a trauma hospital [1]. The total incidence of elbow fractures was $30.8 / 10000$ each year [2]. The majority of injury mechanism comes from fall in an outstretched hand [3].
The complications of elbow fractures include malunion or nonunion of the fracture fragments, stiffness, and neurovascular injury especially the ulnar nerve [4]. Determination of the etiology is important because children's activities are different in each country [2].

There is currently no study about the epidemiology pattern of the elbow in Indonesia, thus we present our study about the epidemiology of elbow fracture pattern in children treated in our institution in nine years of periods from June 2009 until December 2018. 


\section{Methods}

The data of all elbow fractures in children aged 18 years old and younger treated in Saiful Anwar General Hospital Malang in a nine years period of June 2009 to December 2018 were obtained from the medical records. This is a retrospective and descriptive epidemiology study about elbow fracture patterns in pediatric patients. Personal data consisting of age at the time of accidents, fracture sites, type of lesion and ipsilateral injuries, time of the accident and the mechanism of injury were collected and analyzed.

The inclusion criteria are: (1) all elbow fracture cases treated in Saiful Anwar General Hospital Malang whether an outpatient or inpatient care (2) patient with age 18 years old and younger. The exclusion criteria are: (1) patient refused to be treated at our hospital (2) patient who deceased before receiving definitive treatment (3) patient with incomplete data required for this study. No funds were used for the design and conduction of the study; collection, management, analysis, and interpretation of the data; and preparation of the manuscript.

This study was, in part, made possible by using the resources from Saiful Anwar General Hospital Malang and supported by the Ethical Committee for Medical Research of Saiful Anwar General Hospital Malang.

\section{Results}

There were a total of 99 elbow fractures patients meeting the criteria of inclusion; 62 fractures $(63 \%)$ occurred at male patients and 37 fractures $(37 \%)$ occurred at female patients (Table 1). Most cases were supracondylar fracture $(n=77,78 \%)$.

Table 1: Total number of elbow fractures cases based on gender

\begin{tabular}{lc}
\hline Elbow Fractures & \\
\hline Girl & Boy \\
$37 \%$ & $63 \%$ \\
\hline
\end{tabular}

Table 2 shows that from 77 supracondylar fractures, 17 were classified as Gartland type II, and 60 were classified as Gartland type III.

Table 2: Number of elbow fractures cases further classified using classification by Gartland

\begin{tabular}{lccc}
\hline Elbow Fractures & & & \\
\hline Supracondyler Gartland II & Supracondyler Gartland III & Intercondyler & Others \\
17 & 60 & 8 & 14 \\
\hline
\end{tabular}

The most common etiology of fracture is associated with sports and recreational activities and a fall from a height less than two meters. Nerve injuries involving the median, radial, and ulnar nerves were seen in eight patients with Gartland type III supracondylar fracture as we can see in Table 3.

Table 3: Number of associated vascular and nerve injury in supracondylar fractures Gartland type III

\begin{tabular}{lcc}
\hline Supracondyler Fractures Gartland type III & \\
\hline Bony Fractures & Associated Nerve Injury & Associated Vascular Injury \\
48 & 8 & 4 \\
\hline
\end{tabular}

48

Associated vascular injuries happened in four patients with Gartland type III supracondylar fractures. From Table 4 we can see that 78 fractures (79\%) were treated surgically and 21 fractures (21\%) were treated conservatively.

Table 4: Number of elbow fractures cases treated operative and non-operative

\begin{tabular}{lc}
\hline Elbow Fractures Treatment & \\
\hline Operative & Non-Operative \\
78 & 21 \\
\hline
\end{tabular}

\section{Discussion}

From the distribution according to sex in previous study from Esen and Sapmaz and Anjum et al., male patients sustained more elbow fractures compared than female patients [5], [6]. This is in line with the result of our study in which the male patients dominantly suffered elbow fractures than the female patients while a retrospective study about pediatric elbow fractures conducted by Emery et al. showed no differences in the demographic pattern of sex [7].

In this study we divide the elbow fractures patients into four classification of Gartland type II and III, intercondylar, and other type which do not fulfill any of the previous classification. Gartland classification is utilized for the description and orthopaedic management of supracondylar fracture [8]. Gartland type I is a nondisplaced or minimally displaced fracture which is managed conservatively with immobilization. Gartland type II is a displaced fracture with intact posterior cortex and is managed by closed reduction or closed reduction with percutaneous pinning decided by degree of displacement. Gartland type III fracture is defined by complete displacement of fracture with complete cortical disruption of distal humerus. This is commonly managed with closed reduction and percutaneous pinning, and if it fails or there is concurrent brachial artery injury, open reduction is indicated [9]. Gartland type III supracondylar fracture is the commonest type of injury with 60 cases out of 99 patients in our study. It is in majority being the extension type fracture with a common complication such as Volkmann contracture and bone deformity [10]. Similar result about the occurrence of supracondylar fractures is reported by Okubo et al. in the study about pediatric elbow 
fractures. It is reported that the number of supracondylar fractures is the most compared to other elbow fracture in pediatric population with 214 cases from the total of 488 patient populations [2].

From 60 patients sustaining Gartland type III supracondylar fractures, it was found that eight patients suffered a nerve injury (13\%). It is analogous with some previous studies which showed that the nerve injury associated with supracondylar fractures is ranging from $6.4-25 \%$ [11], [12], [13]. The most commonly nerve to be injured in this fracture is the ulnar nerve [4].

The majority of our patients were treated surgically (78 cases). High surgical rate is associated with displaced supracondylar fractures Gartland type III and fractures with neurovascular compromise which need open reduction and exploration surgery. Surgery was chosen to achieve good alignment and to avoid the late complication of elbow deformity such as cubitus varus or 'gunstock deformity'. Conservative treatments were chosen primarily in nondisplaced and isolated elbow fracture which stabilized by immobilization. This is in contrast with the previous epidemiology study from Houshian et al. which applied a much more conservative method for the treatment of the elbow fracture in children [14], but in line with the study investigated by Okubo et al. [2] in the term of higher operative rate for Gartland type II and type III supracondylar fractures $(50 \%$ and $100 \%$ operative rate). In this study, the most common injury is Gartland type III, thus the operative method rate is higher.

In conclusion, pediatric elbow fracture is a common injury caused by fall on an outstretched hand. Supracondylar humeral fracture Gartland type III is the most common classification sustained by patients with elbow fractures and the possibility of neurovascular compromise is always have to be remembered.

\section{Acknowledgement}

The authors of this study want to thank you to all of the staff in Orthopaedic and Traumatology Department, Faculty of Medicine, Universitas Brawijaya for all of the support for this study.

\section{References}

1. Bhat SA, Farouqi RR, Hassan MU, Kirmani TT, Kangoo KA, Baba AN. Epidemiological analysis of elbow fractures in Kashmiri children. Indian J Orthop Surg. 2016; 2(1):48-51 https://doi.org/10.5958/2395-1362.2016.00008.6

2. Okubo H, Nakasone M, Kinjo M, Onaka K, Futenma C, Kanaya F. Epidemiology of paediatric elbow fractures: a retrospective multicentre study of 488 fractures. J Child Orthop. 2019; 13:516-521. https://doi.org/10.1302/1863-2548.13.190043 PMid:31695819 PMCid:PMC6808078

3. Saeed W and Waseem M. Elbow Fractures Overview. StatPearls Publishing, Treasure Island, 2019.

4. Gonzales APM, Delgado-Munoz P, Otero G, Puebla JAL, Vidal $J$. Traumatic elbow injuries: a pictorial review of the most common traumatic elbow injuries, their mechanisms and complications. European Society of Radiology. 2019.

5. Esen M and Sapmaz HI. Epidemiological investigation of traumatic upper extremity fractures in children who applied to emergency department. J Contemp Med. 2018; 8(3):211-217. https://doi.org/10.16899/gopctd.454562

6. Anjum R, Sharma V, Jindal R, Singh TP, Rathee N Epidemiologic pattern of paediatric supracondylar fractures of humerus in a teaching hospital of rural India: A prospective study of 263 cases. Chinese Journal of Traumatology. 2017; 20:158-160. https://doi.org/10.1016/j.cjtee.2016.10.007 PMid:28511800 PMCid:PMC5473711

7. Emery KH, Zingula SN, Anton CG, Salisbury SR, Tamai J. Pediatric elbow fractures: a new angle on an old topic. Pediatr Radiol. 2016; 46(1): 61-6. https://doi.org/10.1007/s00247-0153439-0 PMid:26216157

8. Kim HHR and Gauguet JM. Pediatric Elbow Injuries. Seminars in Ultrasound, CT and MRI. 2018; 39(4):384-396.

https://doi.org/10.1053/j.sult.2018.03.005 PMid:30070231

9. Gartland JJ. Management of supracondylar fractures of the humerus in children. Surg Gynecol Obstet. 1959; 109(2):145-54.

10. Grazina R, Oliveira M, Marinhas J, Ferreira A, Costa A, Rodrigues D, Santos M. Classification of Pediatric Supracondylar Fractures: Comparison between the Gartland and the Lagrange \& Rigault Classifications. Rev Iberam Cir Mano. 2018; 46:113-116. https://doi.org/10.1055/s-0038-1675427

11. Sullivan JA, Gregory JR, Wiley KF, Parris D, Stoner J. Supracondylar Humeral Fracture Documentation: A Performance Improvement Study. J Pediatr Orthop. 2019; 39:e777-e781. https://doi.org/10.1097/BPO.0000000000001372 PMid:31095013

12. Aparicio MJL, Pino AL, Cibrian OARM, Guillen BE, Garcia MM Minguez RMF. Epidemiological study on supracondylar fractures of distal humerus in pediatric patients. Rev Esp Cir Ortop Traumatol. 2019; 63(6):394-399. https://doi.org/10.1016/j.recote.2019.07.004

13. Holt JB, Glass NA, Shah AS. Understanding the Epidemiology of Pediatric Supracondylar Humeral Fractures in the United States: Identifying Opportunities for Intervention. J Pediatr Orthop. 2018; 38(5): e245-e251. https://doi.org/10.1097/BPO.0000000000001154 PMid:29462120

14. Houshian S, Mehdi B, Larsen MS. The epidemiology of elbow fracture in children: analysis of 355 fractures, with special reference to supracondylar humerus fractures. J Orthop Sci. 2001; 6:312-315. https://doi.org/10.1007/s007760100024 PMid:11479758 